\section{Retensi dan Inovasi Fonologis Protobahasa Austronesia (Pan) pada Bahasa Sumbawa (Bs)}

\author{
Mardiah Husnul Fitri Wahid \\ Linguistics Master Program, \\ Universitas Gadjah Mada \\ mardiahfitri96@gmail.com
}

\title{
ABSTRAK
}

Penelitian ini bertujuan mendeskripsikan fonem PAN yang mengalami retensi dan inovasi fonologis pada bahasa Sumbawa (BS) ditinjau dari persepektif diakronis. Data yang digunakan sebanyak 200 kosakata. Pengumpulan data lapangan dilakukan dengan metode simak dan cakap dengan teknik catat dan rekam, metode cakap semuka dengan menggunkan teknik dasar pancing dengan teknik bawahan catat, dan rekam. Data dianalisis dengan menerapkan metode kualitatif deduktif dengan menggunakan metode inovasi bersama dan metode komparatif. Hasil penelitian secara diakronis menunjukkan empat vokal mengalami retensi yaitu /i/, /u/, /a/, / e/, dan terdapat 15 fonem konsonan yang mengalami reesi yaitu /p/, /b/, /t/, /d/, /k/, /g/, $/ \mathrm{m} /, / \mathrm{n} /, / \mathrm{y} /, / \tilde{\mathrm{n}} /, / \mathrm{s} /, / \mathrm{r} /, / \mathrm{l} /, / \mathrm{w} /, / \mathrm{y} /$. Sedangkan untuk fonem PAN yang mengalami inovasi pada BS terdapat beberapa fonem, yang mana beberapa fonem inovasi teratur dan tidak teratur (sporadis). Adapun fonem PAN yang mengalami inovasi tidak teratur atau sporadis yaiu $*_{\mathrm{i}}>\mathrm{e}, *_{\mathrm{u}}>\mathrm{o}, *_{\mathrm{b}}>\mathrm{p}, \mathrm{w}$, dan $*_{\partial}>\partial$, e, $\varepsilon$. sedangkan inovasi teratur fonem PAN pada BS yaitu $*_{\mathrm{z}}>\mathrm{j}, *_{\mathrm{j}}>\mathrm{d}, \mathrm{t}, *_{\mathrm{w}}>\varnothing$, dan $*_{\mathrm{y}}>\varnothing$, inovas kerap terjadi pada posisi awal dan antarvokal pada BS.

Kata Kunci: Protobahasa Austronesia; retensi; inovasi; Sumbawa

\section{PENDAHULUAN}

Bahasa-bahasa mengalami perubahan dan perkembangngan dari bahasa Proto (bahasa tua) sampai ke dalam bahasa yang sekarang kita gunakan. Keraf (1996:29), bahasa proto adalah bahasa tua yang menurunkan sejumlah bahasa-bahasa yang sekerabat: misalnya bahasa Proto-Austronesia adalah bahasa purba dari bahasa-bahasa Indonesia.

Bahasa Proto Austronesia merupakan nama sebuah rumpun bahasa yang mendiami wilayah daratan Asia Tenggara. Selanjutnya, bahasa Proto Austronesia ditulis (PAN). Rumpun bahasa Austronesia dikelompokkan menjadi dua sub-rumpun, yaitu Sub-rumpun Austronesia Barat (bahasa-bahasa Indonesia atau bahasa-bahasa Melayu) dan sub-rumpun Austronesia Timur (bahasa-bahasa Oseania atau bahasa-bahasa Polinesia). kelompok bahasa Indonesia Barat meliputi baha Malagasi, Formosa, Filipina, Minahasa, Aceh, Gayo, Batak, Melayu, Jawa, Madura, Sunda, Nias, Minangkabau, dan kelompok bahasa Indonesia Timur meliputi bahasa Timor-Ambon, Sula-Bacan, Halmahera SelatanIrian Barat (Keraf 1990: 205).

Bahasa Sumbawa termasuk ke dalam rumpun bahasa Austronesia. Sebagai salah satu bahasa yang termasuk dalam rumpun Austronesia, tentu bahasa Sumbawa memiliki persamaan dan perbedaan baik dalam bentuk fonologis, leksikon, maupun gramatikal. Persamaan / pertahanan atau biasa disebut dengan retensi yang muncul dalam bahasa Sumbawa disebabkan oleh pewarisan bahasa proto ke bahasa Sumbawa Sedangkan perbedaan atau inovasi yang terjadi disebabkan oleh masuknya unsur-unsur dari luar yang memberikan variasi dalam bahasa tersebut. Perubahan yang terjadi dapat diketahui melalui sejarah awal timbulnya bahasa dan perkembangannya sampai saat ini melalui linguistik historis komparatif (Hock 1986).

Hubungan kekerabatan bangsa-bangsa ini dapat dibukikan dengan rekonstruksi unsur-unsur retensi (kesamaan atau pemertahanan) maupun inovasi (perubahan) dari bahasa asal yang disebut protobahasa baik pada tataran fonologi, leksikon, maupun gamatikalnya (Masrukhi 2012). Evolusi suatu bahasa dapat dilacak denga cara membandingkan bentuk terkini bahasa tersebut dengan proto 
bahasanya, yaitu dengan cara mengamati perubahan pada aspek yang paling sensitf untuk berubah yaitu pada tataran fonologisnya.

Fokus yang akan dibicarakan dalam tulisan ini adalah retensi dan inovasi protobahasa Austronesia (PAN) pada bahasa Sumbawa (BS), dengan demikian rumusan masalah yang akan coba dibahas dalam tulisan ini adalah, (1) bagaimanakah retensi yang terjadi pada BS terhadap PAN, dan (2) inovasi seperti apa yang terjadi pada PAN terhadap BS. Adapun tujuan dari tulisan ini yaitu mendeskripsikan retensi fonem PAN pada BS, dan mendeskripsikan inovasi apa saja yang terjadi pada BS terhadap PAN.

Beberapa penulis/ peneliti sebelumnya banyak menggunakan bahasa Sumbawa sebagi objek penelitian salah satunya pada bidang historis komparatif. Oleh karena itu beberapa tulisan berikut akan penulis gunakan sebagai kajian pustaka sebagai salah satu acuan dalam menulis.

Aron Meko Mbete (1990) telah melakukan penelitian mengenai "Rekonstroksi Bahasa Protobahasa Bali- Sasak-Sumbawa". Melalui penelitiannya Mbete menjawab hipotesis mengenai kekerabatan bahasa Bali- Sasak - Sumbawa, dengan cara melakukan rekonstruksi terhadap protobahasa BaliSasak -Sumbawa.

Selanjutnya penelitian "Leksikostatistik Bahasa (Sasambo) Bahasa Sasak, Bahasa Sumbawa, dan Bahasa Bima/Mbojo", oleh Hilmi (2017). Penelitian ini mengkaji kekerabatan bahasa (Sasambo) Bahasa Sasak, Bahasa Sumbawa, dan Bahasa Bima/Mbojo dilihat berdasarkan perhitungan persentase kekerabatan, dan jumlah waktu pisah masing-masing bahasa. Hasil penelitian menunjukkan bahwa keempat bahasa tersebut masuk dalam kategori keluarga (family) bahasa. Relevansi penelitian yang dilakukan Hilmi (2017) dengan penelitian ini yaitu objek penelitiannya sama-sama menggunakan bahasa Sasak dan Sumbawa kemudian melihat kekerabatan bahasa dengan menghitung leksikostatistik dan glotokronologi. Perbedaannya tulisan ini membahas pengelompokan kosakata kerabat serta mendeskripsikan korespondensi yang terjadi, sedangkan tulisan Hilmi (2017) hanya mengkaji kekerabatan bahasa melalui penghitungan leksikostatistik dan glotokronologi.

Kemudian penelitian terkait "Retensi dan Inovasi Fonologis Protobahasa Melayik pada Bahasa Melayu Tamiyang" oleh Muhammad Toha (2016). Dalam tulisannya Toha memaparkan retensi serta inovasi yang terjadi pada bahasa Melayu Tamian, dan hasil penelitian yang dapat disimpulkan bahwa bahasa Melayu Tamiang memiliki 17 konsonan dan 4 vokal, yang mana sebagian besar fonem dan vokal Proto Melayik masih dipertahankan keberadaannya oleh bahasa Melayu Tamiang, sedangkan konsonan yang mengalami inovasi berjumlah 6 konsonan.

\section{KERANGKA TEORI}

\section{Rumpun Bahasa Austronesia}

Austronesia dalam definisi umumnya mengacu pada suatu daerah yang dimana bahasa-bahasa Austronesia dituturkan. Daerah tersebut mencakup pulau Taiwan, kepulauan Nusantara (termasuk Filipina), Mikronesia, Melanesia, Polinesia, dan Pulau Madagaskar. Secara harafiah, Austronesia berarti "Kepulauan Selatan" dan berasal dari bahasa Latin austrālis yang berarti "selatan" dan bahasa Yunani nêsos (jamak: nesia) yang berarti "pulau" (www.wikipedia).

Wilhelm von Humboldt (dalam Parera 1991) menunjuk pada kemiripan antara bahasa- bahasa Melayu-Polinesia dan menyebut kemiripan tersebut sebagai rumpun bahasa MelayuPolinesia. Nama bahasa Melayu-Polinesia tetap digunakan sampai sekarang oleh beberapa pakar bahasa untuk merujuk pada bahasa-bahasa Austronesia. Penamaan bahasa Melayu-Polinesia kemudian ditolak oleh oleh Peter W. Schimdt (dalam Parera 1991) pada tahun 1906 dalam bukunya "Die Mon-Khmer Volkerein Bindeglied Zwischen Volkern Zentralasiens und Austronesiens." Schimdt tidak menerima istilah Melayu-Polinesia karena batas Melayu-Polinesia sangatlah sempit. Di sebelah barat wilayah tersebut masih ada bahasa-bahasa Melagasi dan di sebelah timur masih ada bahasa Maori, Hawai dan Rapuni yang memiliki status serumpun. Dalam bukunya pula, Schimdt menawarkan nama baru penyebutan bahasa yang berada dalam wilayah tersebut sebagai rumpun bahasa Austronesia. Disebut rumpun bahasa, karena banyak kosakatanya memiliki kemiripan baik dalam bentuk maupun artinya (kognat). 


\section{Fonem Proto Austronesia}

PAN memiliki empat fonem vokal, yaitu *i, *u, *a, dan *ě. Semua vokal itu dapat muncul pada semua posisi kecuali * ě yang tidak menempati posisi final terbuka. Selain vokal, PAN juga memiliki enam diftong, yaitu, *ay, *aw, *uy, *ey, *ěw dan *iw. Semua diftong hanya menempati posisi final. Konsonan PAN terdiri atas 25 buah konsonan, yaitu *p, *b, $* t, * T, d, * D, * k, * g, * c, * d j, * m, * n, * \eta$,

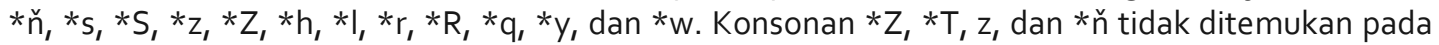
posisi final; sedangkan *j tidak ditemukan pada posisi awal kata. Adapun gugus konsonan yang muncul adalah gugus konsonan nasal yang hanya muncul pada posisi antarvokal (Fernandez 1996: 149-51).

\section{Fonem Bahasa Sumbawa}

Bahasa Sumbawa memiliki bunyi vocal dan konsonan. Terdapat 29 bunyi atau fonem dalam bahasa Sumbawa, yaitu 10 bunyi vokal dan 19 bunyi konsonan (/p/, /b/, /t/, /d/, /c/, /j/, /k/, /g/, /q/, /s/, /h/, /m/, $/ \mathrm{n} /, / \tilde{\mathrm{n}} /, / \mathrm{n} /, \mathrm{r} / \mathrm{l} / \mathrm{l} / \mathrm{l} / \mathrm{w} /$, dan $/ \mathrm{y} /)$. Dengan menggunakan prinsip-prinsip pelambangan bunyi bahasa atau ejaan di atas, dijelaskan bahwa bunyi vokal dilambangkan dengan 8 huruf, yaitu $<i, e, \bar{e}, E, u, o, O$, dan a > sedangkan bunyi konsonan dilambangkan dengan 18 huruf $\langle\mathrm{p}, \mathrm{b}, \mathrm{t}, \mathrm{d}, \mathrm{c}, \mathrm{j}, \mathrm{k}, \mathrm{g}, \mathrm{s}, \mathrm{q}, \mathrm{h}, \mathrm{m}, \mathrm{r}, \mathrm{l}$, w, y, ny, dan ng>. Masing-masing dapat dijelaskan jika huruf <i> melambangkan bunyi /i/; huruf /e/ melambangkan bunyi /e, $\partial, \varepsilon$; huruf <u> melambangkan bunyi /u/; huruf <0> melambangkan bunyi /O/; huruf /O/ melambangkan bunyi /O/; serta /a/ melambangkan bunyi /a/ dan /A/ (bandingkan dengan Burhanuddin 2017).

\section{Retensi dan Inovasi}

Retensi adalah unsur warisan baik maupun arti yang tertinggal atau bertahan pada bahasa-ahasa turunan sama, dengan yang terdapat pada protonya (Anderson 1979: 103; Crowley 1987: 162).

Kaidah-kaidah inovasi yang terjadi pada suatu bahasa dapat dibedakan menjadi dua jenis, yaitu inovasi primer dan inovasi sekunder. Inovasi primer adalah perubahan-perubahan bunyi yang bersifat teratur atau korespondensi (Ino 2015). Perubahan-perubahan bunyi yang korespondensi, yaitu substitusi, split, merger, dan pelesapan (Anttila 2021: 68-70). Substitusi merupakan perubahan sebuah protofonem menjadi fonem lain pada bahasa sekarang. Dengan demikian bisa dikatakan jika dalam proses substitusi terjadi sebuah pergeseran dalam protofonem menjadi fonem lain. Istilah Split atau perengkahan ialah proses perubahan protofonem menjadi dua atau lebih fonem baru yang berbeda pada bahasa sekarang. Split merupakan proses di mana fonem tunggal asli memunculkan dua atau lebih fonem sebagai keturunannya (Keraf 1990: 83; Trask 1996: 268).

Apabila dua fonem atau lebih dari protobahasa mengalami perubahan menjadi satu fonem baru pada bahasa sekarang, inovasi tersebut dinamakan dengan merger atau peleburan (Keraf 1990: 82). Jadi, merger menghilangkan dua atau lebih fonem dari bahasa asalnya. Disamping itu, merger terbagi menjadi dua tipe, yaitu merger bersyarat dan merger tidak bersyarat. Merger bersyarat adalah merger yang hanya berlaku dalam konteks terbatas. Sementara itu, merger tidak bersyarat adalah merger yang berlaku di semua konteks (Trask 1996: 220).

Inovasi sekunder adalah perubahan-perubahan bunyi yang bersifat tidak teratur atau sporadis (Ino 2015). Tipe-tipe perubahan bunyi sporadis ialah lenisi dan fortisi, lowering, metatesis, sinkope, protesis, paragog, pemecahan vokal, asimilasi, dan disimilasi (Crowley 1987: 39-56). Lenisi yaitu perubahan bunyi fonem konsonan dari yang lebih kuat menjadi bunyi yang lebih lemah dan fortisi adalah kebalikan dari lenisi, yaitu perubahan bunyi fonem konsonan yang lebih lemah ( $p, f, h, w, \partial, l$, $\mathrm{l}, \mathrm{s}$, ?) menjadi bunyi fonem konsonan yang lebih kuat (b, p, x, v, a, i, d, s) (Crowley 1987: 39).

\section{METODE PENELITIAN}

Secara umum, data dalam penelitian ini terdiri atas data kebahasaan dan nonkebahasaan. Data kebahasaan terdiri atas lisan dan tulisan. Data kebahasaan lisan adalah data yang dikumpulkan secara langsung di lapangan dengan menggunakan metode simak (Mahsun 2012). Teknik yang digunakan adalah teknik bebas libat cakap atau dalam penelitian kualitatif disebut metode pengamatan/ observasi tidak berpartisipasi, yang didukung oleh teknik dasar catat. Kemudian menggunakan metode cakap semuka (Mahsun 2012) dengan menggunkan teknik dasar pasncing dengan teknik bawahan catat, dan rekam. 
Analisis data dilakukan dengan menggunakan metode inovasi bersama. Menurut Mahsun (2012, 1995) metode inovasi bersama dimaksudkan sebagai cara mengelompokkan bahasa turunan ke dalam suatu kelompok yang lebih dekat hubungannya karena memperlihatkan inovasi bersama secara ekslusif yang menyebar pada bahasa-bahasa yang diperbandingkan. Metode ini lebih dapat dipertanggung jawabkan, lebih-lebih jika bahasa yang diperbandingkan yang memperlihatkan inovasi bersama itu berjauhan letaknya sehingga kesamaan inovasi bersama secara ekslusif itu bukan sebagai hasil pinjaman atau pengaru memengaruhi satu sama lain. Inovasi bersama secara linguistik tersebut dapat mencangkuptataran bunyi, imbuhan, kalimat, kosakata, maupun makna.

Kemudian menggunakan metode komparatif yang bersifat kualitatif (Sudaryanto 2015). Langkah penggunaan metode ini adalah dengan merekonstruksi hubungan antarbahasa dengan cara merunutnya berdasarkan anasir warisan fonem dari peringkat yang lebih tinggi (PSS) ke tingkat yang lebih rendah (BS). Ini dilakukan untuk menentukan unsur-unsur yang mengalami inovasi dalam bahasa Melayu Tamiang yang digunakan pada saat sekarang. Adapun protobahasa yang digunakan dari hasil rekonstruksi bahasa Sasak-Sumbawa atau Protobahasa Sasak-Sumbawa (PSS) Mbete (1990).

Penyajian hasil analisis data termasuk linguistik historis dilakukan dengan dua cara, yaitu metode nonformal dan metode formal. Metode nonformal maksudnya penyajiannya menggunakan katakata biasa termasuk penggunaan terminologi teknis, sedangkan metode formal menggunakan tanda atau lambang seperti tanda asteris (*).

\section{HASIL DAN PEMBAHASAN}

\section{Retensi Vokal}

Retensi fonologis bahasa Sumbawa dilakukan terhadap semua fonem PAN yang mungkin terdapat dalam bahasa Sumbawa. Seperti yang telah disebutkan sebelumnya bahwa PAN memiliki empat fonem vokal yaitu *i, *u, *a, dan *e. semua vokal dapat dapat muncul pada semua posisi kecuali *ě. Berikut hasil penelusuran retensi PAN pada bahasa Sumbawa.

\section{a. *i PAN $\rightarrow$ i pada BS pada setiap posisi}

\begin{tabular}{llll} 
PAN & \#v- & -v- & -v\# \\
\hline$*_{\mathrm{i}}$ & $*$ ipaR $\rightarrow$ ipaR 'ipar' & *linDuR $\rightarrow$ linir 'gempa kecil' & $*$ api $\rightarrow$ api 'api' \\
& $*$ ina $\rightarrow$ inaq 'ibu' & *tipis $\rightarrow$ ripis 'tipis' & $*$ taqi $\rightarrow$ tai 'tai' \\
\hline
\end{tabular}

Vokal *i PAN juga tidak mengalami perubahan pada bahasa Sumbawa, baik pada posisi \#v- dan posisi -v-, maupun posisi ultima terbuka (-v\#) *i PAN tidak mengalami perubahan atau retensi.

\section{b. *U PAN $\rightarrow$ u pada BS pada setiap posisi}

Vokal *u PAN u BS mengalami retensi atau pemertahanan pada bahasa Sumbawa, pada semua posisi, baik pada posisi ultima, di tengah kata, maupun penultima.

\begin{tabular}{llll}
\hline PAN & \#v- & -v- & -v\# \\
\hline *u & *ujan $\rightarrow$ ujan 'hujan' & *dua $\rightarrow$ dua 'dua' & * batu $\rightarrow$ batu 'batu' \\
& *ulat $\rightarrow$ ulat 'ulat' & *bulan $\rightarrow$ bulan 'bulan' & * tebusu $\rightarrow$ tebu 'tebu' \\
\hline
\end{tabular}

Pada contoh tersebut tampak bahwa vokal /u/ dipertahankan atau diwariskan menjadi bunyi [U] dalam bahasa Sumbawa pada semua posisi. Artinya, vokal/u/mengalami retensi atau pemertahanan dalam bahasa Sumbawa.

\section{c. ${ }^{*} \partial \mathrm{PAN} \rightarrow$ ə pada BS}

Vokal / ə / memiliki alofon [ə, $\varepsilon$, e]. Alofon dari vokal * ə PAN diwariskan menjadi [ə] dalam bahasa Sumbawa sama-sama dapat menempati posisi /\#v-, -v-, dan -vk\#. 


\begin{tabular}{llll}
\hline PAN & \#v- & -v- & -v\# \\
\hline \multirow{2}{*}{ * } & *ənam $\rightarrow$ ənam 'enam' & *pagər $\rightarrow$ dua 'dua' & * matə $\rightarrow$ matə 'mati' \\
& *əmpat $\rightarrow$ əmpat 'empat' & *təbu $\rightarrow$ təobu 'təbu' & * \\
\hline
\end{tabular}

Pada contoh tersebut tampak bahwa vokal /ə/ dipertahankan atau diwariskan menjadi bunyi [ə] dalam bahasa Sumbawa pada semua posisi. Artinya, vokal ə/ mengalami retensi atau pemertahanan dalam bahasa Sumbawa.

\section{d. *a PAN $\rightarrow$ a pada BS}

\begin{tabular}{llll}
\hline PAN & \#v- & -v- & -v\# \\
\hline *a & *anin $\rightarrow$ anin 'angin' & *kaqan $\rightarrow$ kakan 'makan' & * duwa $\rightarrow$ dua 'dua' \\
& *ajaR $\rightarrow$ ajaR 'ajar' & *tama $\rightarrow$ tama 'masuk' & * buka $\rightarrow$ buka 'membuka' \\
\hline
\end{tabular}

Pada contoh tersebut tampak bahwa vokal /a/ dipertahankan atau diwariskan menjadi bunyi [a] dalam bahasa Sumbawa pada semua posisi. Artinya, vokal ə/ mengalami retensi atau pemertahanan dalam bahasa Sumbawa.

\section{Retensi Konsonan}

Konsonan PAN terdiri atas 25 buah konsonan, yaitu *p, *b, *t, *T, d, *D, *k, *g, *c, *dj, *m, *n, *n,

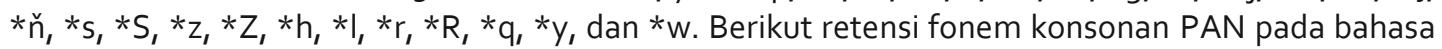
Sumbawa.

\begin{tabular}{|c|c|c|c|}
\hline PAN & \#k- & $-k-$ & $-k \#$ \\
\hline \multirow[t]{2}{*}{ *p } & *pənuq $\rightarrow$ pənoq 'penuh' & *apuy $\rightarrow$ api 'api' & * qatap $\rightarrow$ atap 'atap' \\
\hline & *putiq $\rightarrow$ putiq 'putih' & *qapit $\rightarrow$ apit 'mengapit' & * hiRup $\rightarrow$ irup 'menghirup' \\
\hline \multirow[t]{3}{*}{ *b } & *butuq $\rightarrow$ butuq 'penis' & *tumbu $\rightarrow$ tumbuq & \\
\hline & *batu $\rightarrow$ batu 'batu' & 'tumbuh' & \\
\hline & & * təbu $\rightarrow$ təbu 'təbu' & \\
\hline \multirow[t]{2}{*}{$* \mathrm{t}$} & *tuRun $\rightarrow$ turun 'turun' & *qatey $\rightarrow$ ate 'hati' & *takut $\rightarrow$ takut 'takut' \\
\hline & *taqi $\rightarrow$ tai 'tai' & *putiq $\rightarrow$ putiq 'putih' & *sakit $\rightarrow$ sakit 'sakit' \\
\hline \multirow[t]{2}{*}{$* d$} & *damay $\rightarrow$ dame 'damai' & *aDan $\rightarrow$ adan 'arang' & \\
\hline & *dahun $\rightarrow$ din 'daun' & *linDur $\rightarrow$ lindur 'gempa' & \\
\hline \multirow[t]{2}{*}{$* \mathrm{k}$} & *kulit $\rightarrow$ kulit 'kulit' & *bəkal $\rightarrow$ bəkal 'bekal' & *manuk $\rightarrow$ manuk 'ayam' \\
\hline & *kara $(\mathrm{Ct}) \rightarrow$ karat 'karat' & *(t)ikar $\rightarrow$ tikar 'tikar' & *piyak $\rightarrow$ piak 'membuat' \\
\hline \multirow[t]{2}{*}{$* g$} & *gaday $\rightarrow$ gade 'gadai' & *pagəR $\rightarrow$ pagər 'pagar' & \\
\hline & $\begin{array}{c}\text { *guncan } \rightarrow \text { guncap } \\
\text { 'guncang' }\end{array}$ & *jagah $\rightarrow$ jaga 'jaga' & \\
\hline \multirow[t]{2}{*}{ *m } & *miñak $\rightarrow$ *miñak 'minyak' & *tama $\rightarrow$ tama 'masuk' & *inum $\rightarrow$ inum 'minum' \\
\hline & *maCa $\rightarrow$ mata 'mata' & *damay $\rightarrow$ dame 'damai' & *asəm $\rightarrow$ asəm 'asam' \\
\hline
\end{tabular}




\begin{tabular}{|c|c|c|c|}
\hline \multirow[t]{2}{*}{ *n } & *nannaq $\rightarrow$ nanaq 'nanah' & *ina $\rightarrow$ ina 'ibu' & *quZan $\rightarrow$ ujan 'hujan' \\
\hline & *(n)aqay $\rightarrow$ nae 'kaki' & *panaq $\rightarrow$ panaq 'panah' & *kawanan $\rightarrow$ kanan 'kanan' \\
\hline \multirow[t]{2}{*}{$* \eta$} & 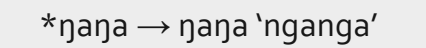 & *anin $\rightarrow$ anin 'angin' & *qudan $\rightarrow$ uyạ 'udang' \\
\hline & *nilu $\rightarrow$ nilu 'ngilu' & *təџaq $\rightarrow$ təџaq 'tengah' & *Rəbun $\rightarrow$ Rəbun 'rebung' \\
\hline \multirow[t]{2}{*}{ *ñ } & *ñiuR $\rightarrow$ ñuR 'kelapa' & *pəñu $\rightarrow$ pəñu 'penyu' & \\
\hline & *ñata $\rightarrow$ ñata 'nyata' & *ñañi $\rightarrow$ ñañi 'nyanyi' & \\
\hline \multirow[t]{2}{*}{ *s } & *siwa $\rightarrow$ siwa 'sembilan' & *basaq $\rightarrow$ basaq 'basah' & *dəRəs $\rightarrow$ dəres 'deras' \\
\hline & *salaq $\rightarrow$ salaq 'salah' & *Rusuq $\rightarrow$ Rusuq 'rusuk' & *tikus $\rightarrow$ tikus 'tikus' \\
\hline \multirow[t]{2}{*}{$*_{r}$} & *ratus $\rightarrow$ ratus 'ratus' & *kərət $\rightarrow$ kərət 'memotong' & *ta $(\mathrm{m}) \mathrm{baR} \rightarrow$ tabar 'tawar' \\
\hline & *Rəbaq $\rightarrow$ rebaq 'tumbang' & $\star$ turut $\rightarrow$ turut 'turut' & *bibir $\rightarrow$ biyar 'bibir' \\
\hline \multirow[t]{2}{*}{ *1 } & *lumut $\rightarrow$ lumut 'lumut' & *qulaj $\rightarrow$ uləd 'ulat' & *təbel $\rightarrow$ təbəl 'tebal' \\
\hline & $\begin{array}{c}\text { *ləbur } \rightarrow \text { lebur } \\
\text { 'menghancurkan' }\end{array}$ & *bulan $\rightarrow$ bulan 'bulan' & *səlsəl $\rightarrow$ səsal 'menyesal' \\
\hline \multirow[t]{2}{*}{$*_{w}$} & & $* \operatorname{liw} ə(\mathrm{Ct}) \rightarrow$ liwat 'melewati' & \\
\hline & & *gawa(h) $\rightarrow$ gawe 'bekerja' & \\
\hline \multirow[t]{2}{*}{ *y } & & *bayar $\rightarrow$ bayar 'bayar' & \\
\hline & & *layar $\rightarrow$ layar 'layar' & \\
\hline
\end{tabular}

Berdasarkan pemaparan contoh data tersebut, konsonan PAN yang mengalami retensi pada BS terdapat 15 fonem konsonan yaitu /p/, /b/, /t/, /d/, / / /, /g/, /m/, /n/, / / /, / /n/, /s/, /r/, /l/, /w/, dan /y/. Fonem konsonan yang mengisi posisi awal, tengah dan akhir yaitu terdapat 9 fonem konsonan yaitu $/ \mathrm{p} / \mathrm{l} / \mathrm{t} /$, /k/, /m/, /n/, / / /, /s/, /r/, dan /l/. Sedangkan fonem konsonan BS yang hanya mengisi posisi awal dan tengah terdapat 4 fonem yaitu /b/, /d/, /g/, dan /ñn/. Fonem /w/ dan /y/ hanya mengisi posisi tengah.

\section{3.3 Inovasi Vokal}

Selain mengalami retensi, beberapa fonem vokal PAN mengalami inovasi pada BS.

\section{a. *i PAN > e BS}

*tumid > tumed 'tumid'

*dindin > denden 'dendeng'

*timpan > tempan 'pincang'

Terlihat fonem PAN *i mengalami inovasi menjadi /e/ pada BS pada suku pertama dan posisi penultimma. PAN *i mengalami inovasi tidak teratur menjadi /e/ pada BS seperti yang terlihat pada tiga etimon di atas.

\section{b. *u PAN > o BS}

$$
\begin{aligned}
& \text { *cuba > coba 'coba' } \\
& \text { *humbak > ombak 'ombak' } \\
& \text { *pənuq > pənoq 'penuh' }
\end{aligned}
$$

Selain mengalami retensi, PAN *u ternyata mengalami beberapa inovasi menjadi /o/ pada sejumlah etimon BS. Inovasi yang terjadi secara tidak teratur pada suku pertama maupun pada suku kedua, baik pada suku terbuka maupun pada suku tertutup. 
c. *əPAN $>/ \partial, e, \varepsilon / B S$

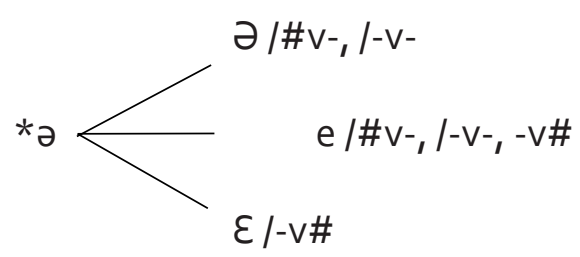

Vokal *ə PAN mengalami inovasi sporadis, yaitu berupa alofon /ə, e, $\varepsilon /$ dalam BS. Inovasi yang terjadi juga merupakan inovasi yang tidak teratur yang mana alofon BD dapat mengisi posisi penultima dan posisi tengah (/\#v-, /-v-) terjadi pada alofon BS/ə/, sedangkan alofon /e/ dapat mengisi setiap posisi ( /\#v-, / - v-, - - \#\#)dalam BS. Alofon / $/$ / merupakan alofon yang hanya dapat mengisi posisi ultima atau akhir (/-v\#).

\section{Inovasi Konsonan}

\section{a. *b PAN > p dan w BS}

$$
\begin{aligned}
& \text { *b } \\
& \text { * bətun > pətun 'bambu' } \\
& \text { *təkup > təkəp 'menutup' } \\
& \text { *laban > lawan 'lawan' }
\end{aligned}
$$

PAN *b mengalami inovasi yang tidak teratur menjadi fonem /p/ dan /w/ dalam BS. Pada posisi awal ditemukan sebuah contoh inovasi *b> p, inovasi yang sama terjadi pula pada posisi akhir. Kemudian inovasi yang tidak teratur terjadi pada posisi tengah yaitu pada posisi antarvokal, *b PAN menjadi *w pada BS.

\section{b. *z PAN > j BS /\#- dan /-k-}

*zeret > jerat 'jerat'

*zaqit > jait 'jahit'

*azar > ajar 'ajar'

*tazim > tajam 'tajam'

PAN *z mengalami inovasi teratur menjadi /j/ pada BS. Inovasi yang teratur ditermukan pada posisi awa dan antarvokal (/\#- dan /-k-).

\section{c. *j PAN > d, t BS}

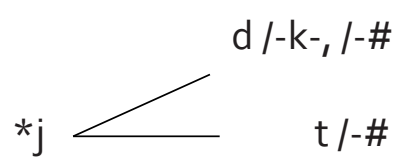

$$
\begin{aligned}
& \text { *ijusun > idun 'hidung' } \\
& \text { *bajaq > badaq 'memberitahukan' } \\
& \text { *qulaj > ulad 'ulat' } \\
& \text { *kuñij > kuñit 'kunyit' } \\
& \text { *pusəj > pusat 'pusat' }
\end{aligned}
$$


Seperti yang terlihat pada etimon-etimon di atas, PAN *j mengalami inovasi menjadi /d/ pada BS, khususnya pada posisi antarvokal (-k-). Pada posisi akhir (/-\#), perubahan itu hanya ditemukan pada satu etimon saja. Kedua etimon lainnya menunjukkan inovasi PAN *j > t pada BS /-\#.

d. *w PAN > ø BS /\#-, -k-

*waSiR > aiq 'air'

*waDaq > adaq 'ada'

*tawu > tau 'orang'

*kuwat > kuat 'kuat'

PAN $*_{w}$ akan mengalami peluluhan fonem pada BS. PAN *w mengalami inovasi tidak teratur menjadi /ø/ pada posisi awal (/\#-) BS. Sedangkan PAN *W akan mengalami inovasi teratur pada menjadi /ø/ pada posisi antarvokal, jikalau didahului dan diikuti oleh /u/.

e. *y PAN >ø BS / -k-

*piyak > piak 'membuat'

*tiyan > tian 'perut'

*tiyup > tiup 'meniup'

PAN *y akan mengalami peluluhan fonem pada BS. PAN *y akan mengalami inovasi teratur pada menjadi /ø/ pada posisi antarvokal, jikalau didahului dan diikuti oleh /u/.

\section{KESIMPULAN}

Berdasarkan hasil analisis data, fonem vokal yang mengalami retensi PAN pada BS terdapat empat vokal yaitu /i/, /u/, /a/, dan /e/. Semua vokal yang mengalami retensi dapat muncul pada semua posisi. Sementara konsonan PAN yang mengalami retensi pada BS terdapat 15 fonem konsonan yaitu /p/, /b/, /t/, /d/, / k/, /g/, /m/, /n/, / / /, / $\tilde{\mathrm{n}} /$, /s/, /r/, /l/, /w/, dan /y/. Fonem konsonan yang mengisi posisi awal, tengah dan akhir yaitu terdapat 9 fonem konsonan yaitu /p/, /t/, /k/, /m/, /n/, / / /, /s/, /r/, dan /l/. Sedangkan fonem konsonan BS yang hanya mengisi posisi awal dan tengah terdapat 4 fonem yaitu /b/, /d/, /g/, dan /ñ/. Fonem /w/ dan /y/ hanya mengisi posisi tengah.

Sedangkan untuk fonem PAN yang mengalami inovasi pada BS terdapat beberapa fonem, yang mana beberapa fonem inovasi teratur dan tidak teratur (sporadis). Adapun fonem PAN yang mengalami inovasi tidak teratur atau sporadis yaiu $* i>e, * u>0, * b>p, w, d a n * \partial>\partial, e, \varepsilon$. sedangkan inovasi teratur fonem PAN pada BS yaitu ${ }^{*} \mathrm{z}>\mathrm{j},{ }^{*} \mathrm{j}>\mathrm{d}, \mathrm{t},{ }^{*} \mathrm{w}>\varnothing$, dan ${ }^{*} \mathrm{y}>\varnothing$, inovas kerap terjadi pada posisi awal dan antarvokal pada BS.

\section{DAFTAR PUSTAKA}

Anderson, James M. 1979. Structural Aspects of Language Change. London: Longman.

Anttila, Raimo. 2021. Historical and Comparative Linguistics. Cilt.6. John Benjamins Publishing Company. Diakses Agustus 6. https://benjamins.com/catalog/cilt.6.

Burhanuddin. 2017. "Hubungan Kekerabatan Bahasa Subrumpun Halmahera Selatan-Papua Barat Di Halmahera Selatan." Disertasi, Solo: Universitas Sebelas Maret. https://pasca.uns.ac.id/szlinguistik/2017/06/22/hubungan-kekerabatan-bahasa-subrumpunhalmahera-selatan-papua-barat-di-halmahera-selatan/.

Crowley, Terry. 1987. An Introduction to Historical Linguistics. Port Moresby: University of Papua New Guinea Press.

Fernandez, Inyo Yos. 1996. Relasi historis kekerabatan bahasa Flores: kajian linguistik historis komparatif terhadap sembilan bahasa di Flores. Ende, Flores, NTT, Indonesia: Nusa Indah.

Hilmi, Moh. 2017. "Leksikostatistik Bahasa (Sasambo) Bahasa Sasak, Bahasa Sumbawa/Samawa, Dan Bahasa Bima/Mbojo: Kajian Linguistik Historis Komparatif." FONDATIA 1 (1): 165-76. doi:10.36088/fondatia.vi11.94. 
Hock, Hans Heinrich. 1986. Principles of Historical Linguistics. Berlin: Mouton de Gruyter.

Ino, La. 2015. "Pemanfaatan Linguistik Historis Komparataif Dalam Pemetaan Bahasa-Bahasa Nusantara." RETORIKA: Jurnal Ilmu Bahasa 1 (2): 365-78. doi:10.22225/jr.1.2.41.365-378.

Keraf, Gorys. 1990. Linguistik bandingan tipologis. Disunting oleh Pamusuk Eneste. Jakarta: Gramedia.

Mahsun. 1995. Dialektologi Diakronis. Yogyakarta: Gajah Mada University Press.

- 2012. Metode penelitian bahasa: tahap strategi, metode, dan tekniknya. Jakarta: Rajawali Press.

Masrukhi, Moh. 2012. "Refleksi Fonologis Protobahasa Austronesia (PAN) Pada Bahasa Lubu (BL)." Humaniora 14 (1): 86-93. doi:10.22146/jh.749.

Mbete, Aron Meko. 1990. "Rekontruksi proto bahasa Bali Sasak Sumbawa." Disertasi, Depok: Universitas Indonesia. https://opac.perpusnas.go.id/DetailOpac.aspx?id=625230.

Parera, Jos Daniel. 1991. Kajian linguistik umum historis komparatif dan tipologi struktural. Jakarta, Indonesia: Erlangga.

Sudaryanto. 2015. Metode dan aneka teknik analisis bahasa: pengantar penelitian wahana kebudayaan secara linguistis. ILDEP. Yogyakarta: Duta Wacana University Press.

Toha, Muhammad. 2016. "Retensi Dan Inovasi Fonologis Protobahsa Melayik Pada Bahasa Melayu Tamiang." Ranah: Jurnal Kajian Bahasa 5 (1): 87-100. doi:10.26499/rnh.v5i1.40.

Trask, Robert Lawrence. 1996. Historical Linguistics. London: Arnold. 